\title{
Pediatrik Hastaların Preoperatif Değerlendirmesi
}

\author{
${ }^{1}$ Çă̆ıl Vural \\ ${ }^{1}$ Ankara Üniversitesi Diş Hekimliği Fakültesi Ağız Diş Çene Cerrahisi AD \\ e-posta: mdcagil@hotmail.com
}

\begin{abstract}
GİRIŞ: Pediatrik anestezide mortalite oranları gelişen anestezik yaklaşımlar ve artan bilgi birikimiyle her ne kadar azalsa da, perioperatif morbiditeyi vurgulayan yayınlar günümüzde hala mevcuttur. $\mathrm{Bu}$ hastalarda tam ve eksiksiz bir preoperatif değerlendirme mortalite ve morbidite oranlarının azalmasında kilit basamaklardan birisidir. Her ne kadar anestezi alacak çocukların çoğu sağlıklı olsa da altta yatan hastalıkların erkenden teşhis edilmesi perioperatif süreçte karşılaşılacak komplikasyonları en aza indirger. Yine çocukların anatomik ve fizyolojik farklılıklarının olması da bu hastalara yaklaşımda her zaman göz önünde bundurulmalıdır. Hastaların değerlendirilmesinde çocuk için stres yaratacak her faktör en aza indirgenmelidir. Gerek çocuk gerekse ailesi için ayrı bir stres kaynağı olan rutin testler, anamnez ve fizik muayeneden bağımsız olarak istenmemeli, preoperatif değerlendirmede elde edilen bulgulara yönelik seçici testler uygulanmalıdır. Hastanın temel fizik muayenesi havayolu, solunum sistemi ve kardiyopulmoner sistem değerlendirmesinden oluşur. Bunlar dişında nöromusküler ve endokrin sistem muayeneleri yapılmalı ve mevcut hastalıklarına yönelik hazırlıklı olunmalıdır. Bu derleme çocuk hastaların anestezi öncesi değerlendirmelerinde ve hazırlıklarında dikkat edilmesi gereken hususları vurgulamaya çalışacaktır.
\end{abstract}

ANAHTAR KELIMMELER: preoperatif değerlendirme, anestezi, çocuk hastalar, morbidite

INTRODUCTION:Even though the mortality rates are decreasing with developing anesthetic approaches and increasing of knowledge in pediatric anesthesia, reports emphasizing the perioperative morbidity still remain. A complete preoperative evaluation of these patients is one of the key steps of the decreased mortality and morbidity rates. Although the majority of the children who are planned to get anesthesia are healthy, the early detection of underlying comorbidities minimizes the complications in the perioperative period. Furthermore, the anatomical and physiological differences between children should always be taken into account. During the evaluation, every factor that may put the child under stress should be reduced to a minimum. Routine tests which may be individual stress factors for both the child and the parents should not be demanded separately from the time of anamnesis and physical examination but selective tests should be applied intended for the findings in preoperative evaluation. The basic physical examination of the patient is comprised of airway, respiratory system and cardiopulmonary system evaluation. Also neuromuscular and endocrine systems examinations should be done, and should be prepared for the current disease This review aims to emphasize the points that should be paid attention to while evaluating pediatric patients prior to and during the preparation for anesthesia.

KEY WORDS: preoperative assessment, anesthesia, pediatric patients, morbidity

\section{Pediatrik Hastaların Preoperatif Değerlendirmesi}

Pediatrik anestezide mortalite oranları gelişen anestezik yaklaşımlar ve artan bilgi birikimiyle her ne kadar azalsa da, perioperatif morbiditeyi vurgulayan yayınlar günümüzde hala mevcut. $\mathrm{Bu}$ hastalarda tam ve eksiksiz bir preoperatif değerlendirme mortalite ve morbidite oranlarının azalmasında kilit basamaklardan birisidir. Her ne kadar anestezi alacak çocukların çoğu sağlıklı olsa da altta yatan hastalıkların erkenden belirlenmesi perioperatif süreçte karşılaşılacak problemleri en aza indirger. Yine çocukların anatomik ve fizyolojik farklilıklarının olması da bu hastalara yaklaşımda her zaman göz önünde bundurulmalıdır. Hastaların değerlendirilmesinde çocuk için stres yaratacak her faktör ki buna gereksiz yapılan testler de dahil, en aza indirgenmelidir. $\mathrm{Bu}$ özet çocuk hastaların anestezi öncesi 
değerlendirmelerinde ve hazırlıklarında dikkat edilmesi gereken hususları vurgulamaya çalışacaktır. Anestezi alacak tüm hastalarda olduğu gibi çocuk hastalarda anestezi öncesi değerlendirilmelidir.

Preoperatif değerlendirme güvenli bir anestezi ve başarılı bir perioperatif süreç için çok önemlidir ve anestezistin çocuk ve ailesiyle ilk karşılaşması ile başlar. Bu değerlendirme hastanın klinik hikayesi, tamamlayicı tetkikler, hasta ve ebeveynlerinin bilgilendirilmesi ve psikolojik olarak hazırlanmalarını içerir [1].

Detayl1 bilgilendirme ebeveynlerin zihinlerindeki soru işaretlerini kaldırır ve işbirliğini artırır. Değerlendirme sürecinde hasta ve yakınlarının zaten mevcut olan stresleri gereksiz testler ve klinik konsültasyonlar ile artabilir. $\mathrm{Bu}$ nedenle anamnez ya da klinik muayede herhangi bir özellik yoksa gereksiz tetkiklerden kaçınılmalıdır[2][3].

Anamnez gestasyondan başlamalı, mevcut tanı ve tedavileri sorgulanmalıdır. Aile öyküsü ve kullandığı ilaçlar ve aşıları sorgulanmalıdır. Hastanın temel fizik muayenesi havayolu, solunum sistemi ve kardiyopulmoner sistem değerlendirmesinden oluşur [2].

Solunum sistemi Solunum sistemi problemleri pediatrik hasta grubunda karşılaşılacak en büyük problemlerden birisidir [4-6]. Fonksiyonel rezidüel kapasitelerinin düşük olmasından dolayı daha düşük oksijen rezervleri vardır ve dolayısıyla hipoksiye daha yatkındırlar [6]. Gögüs duvarı kompliyanslarının yüksek olması akciğer basıncının düşük olmasına, buna bağlı olarak da kollabe olma oranının artmasına yol açar [7-9]. Yaşla birlikte gögüs duvarı kompliyansı azalmasıyla kollaps riski de azalır [10].

Havayolu değerlendirmesi standart olarak çocuklara da uygulanmalı, ağız açıklığı ve boyun hareketleri değerlendirilmelidir. Çocukların mevcut anatomileri iyi algılanırsa, entübasyonları erişkinlerden daha kolay bile olabilir.

İnfantların larinksi erişkinlere göre (C4-5) daha yüksektir (C3-4). Epiglotları büyüktür fakat dar ve kısadır. $\mathrm{Bu}$ anatomik özelliklerden dolayı, düz bladeli laringoskop infantda larinksin daha kolay görünebilir olmasına izin verir.

İnfantların vokal kordları eğimlidir, arka komissur ön komissura göre daha sefaldedir. Larinksin bu düzeni anterior sublaringeal havayolunu endotrakeal tüple hasarlanmasına daha yatkın hale getirir. Subglottik bölge tüpe bağlı travmatik hasara eğilimlidir çünkü infant larinksinin en dar bolumu krikoid kıkırdak hizasındadır. Yetişkinlerde, en dar kısım glottik kenardır. Böylece, bebek veya çocukta vokal kordları kolaylıkla geçen endotrakeal tüp subglottise rahatlikla oturur ve subglottik ödem ve ekstübasyondan sonra artmış havayolu direnç semptomlarına yol açar. $\mathrm{Bu}$ artmış direnç sıklıkla geri dönüşlüdür, fakat büyük endotrakeal tüple uzun süreli entübasyondan sonra subglottik stenoz gelişebilir. İnfantların vagal tonusu daha yüksektir. Bunun sonucu olarak sekresyon, aspirasyon gibi havayolu irritabilitesini artıran durumlar apne ve laringospazm gelişme olasılığını artırırlar $[11,12]$.

Laringospazm gelişme oranı çocuklarda, erişkinlere göre daha yüksek olduğundan dolayı preoperatif değerlendirmede astım, üst solunum yolu enfeksiyonu ve pasif sigara içiciliği gibi etkenler mutlaka sorgulanmalıdır $[5,7,13,14]$.Üst solunum yolu enfeksiyonları (ÜSYE) çocuklarda daha sik görülür [15]. Solunum yolu enfeksiyonları bulunan çocuklarda sağlıklı çocuklara göre havayolu komplikasyonları gelişme oranı daha yüksektir [8, 13]. ÜSYE çocuklarda havayolu reaktivitesini 6 haftaya kadar uzatabilir [16, 17]. ÜSYE'si bulunan bir hastanın anestezi 
almas1 laringospazm [7], bronkospazm [8], atelektazi ve oksijen desatürasyonuna zemin hazırlar [18] . Bu nedenle operasyon ve anestezi planı buna göre yapılmalı, öksürük, konjesyon, ateş gibi fizik muayene bulguları olan elektif cerrahiler 4-6 hafta ertelenmelidir [19].

Kardiyovasküler sistem Kardiyovasküler sistem değerlendirmesinde, masum sistolik üfürümler çocuklarda sıktır ve çoğunlukla fonksiyoneldir. $\mathrm{Bu}$ üfürümlerin konjenital kalp hastalığı açısından dikkatli muayene edilmesi, çocuğun hem oturarak hem de supin pozisyonda oskültasyonu önemlidir. İleri derecede üfürümler supin pozisyonda şiddetlenecektir. Pansistolik, diastolik, 2/6 dereceden büyük üfürümler ileri tetkik gerektirirler. Prematüritelik, gelişme geriliği, konjenital malformasyonlar da kardiyak patolojiler için risk faktörleridirler. Mevcut kalp hastalığı olan çocuklarda endokardit profilaksisi cerrahi tipine göre belirlenir [20]. Birçok anestezik ajansistemik ve pulmoner vasküler rezistansta azalmaya yol açar. Buna bağlı olarak mevcut kardiyak şantlarda değişiklik meydana gelebilir. Soldan sağa şantlar hipoksi, asidoz, hipotermi gibi durumlarda pulmoner vasküler rezistansta ki artışa bağlı sağdan sola değişebilir [19].

Nüromuskuler sistem Potent inhalasyon anestetikleri motor refleks cevab1 ve koordinasyonu bozması ve bu etkinin anestezi kesildikten sonra saatlerce sürmesi nedeniyle daha önce mevcut santral veya periferik nöromusküler anomaliler preoperatif ortaya konulmalıdır. Nöromusküler ve dejeneratif hastalığı olanlarda postoperatif güçsüzlük uzamış mekanik ventilasyona neden olacağından anesteziyolog altta yatan patolojiyi ve derecesini preoperatif dönemde bilmelidir. Preoperatif hazırlık döneminde malign hipertermi, konnektif doku hastalığ 1 ve kemoterapi altındaki çocuklar dikkatlice değerlendirilmelidir. Malign hipertermi son derece letal seyreden akut hipermetabolizma durumu olup, bazı inhalasyon anestezikleri ve süksinilkolin bu olayın başlamasında tetiği çekebilmektedir. Malign hipertermi şüphesinde hasta ve ailesi ile ilgili hikaye dikkatlice değerlendirilmeli, geçirdiği ameliyatlar, ve ailede ölümler detaylı bir şekilde araştırılmalıdır. $\mathrm{Bu}$ hastaların anestezisinde propofol, opioidler, barbitüratlar, benzodiazepinler ve lokal anestezikler planlanmalıdır.

Endokrin sistem Anestezi ve cerrahi çocuk için son derece önemli bir strestir. $\mathrm{Bu}$ stresle epinefrin, norepinefrin, kortizol miktarında artış, insülin-glukagon ilişkisinde değişiklik, cerrahiden sonraki günde katabolik süreçte devamlılık görülür [21]. $\mathrm{Bu}$ nedenle çocuğun cerrahiden önce mümkün olabilecek en iyi nütrisyonel durumda olması gerekir. Preoperatif açlığa rağmen cerrahi stres hiperglisemik cevap oluşturur. Bir yaşın altındaki bebeklerde ve prematürelerde açlık preoperatif hipoglisemi ile sonuçlanabilir. Çocukluk çağı obezitesi hızla artmaktadır. Obez çocuklar perioperatif komplikasyon gelişimi açısından normal çocuklara göre iki kat risk altındadırlar [22]. Astım ve solunum yolu enfeksiyonları da daha siktır. Hipertansiyon, gastroözofageal reflü, obstrüktif uyku apne sendromu gibi problemler de daha s1k görülür [22, 23]. Çocuklarda diyabet prevalansı obeziteyle paralel olarak artmaktadır [24]. Bu çocukların kan glukoz seviyeleri ve elektrolit imbalansları dikkatli takip edilmelidir. Cerrahileri uzamış açlık süresinden kaçınılarak erken planlanmalıdır [21]. Uzun süreli kortikosteroid tedavisi altındaki hastalar ve konjenital adrenal yetmezliği olan hastalarda hipotalamik pituiter adrenal aksinda supresyon vardır. $\mathrm{Bu}$ nedenle bunlar stres cevabı gösteremezler ve hemodinamik uyumsuzluk gösterirler. Değişik hastalıklar nedeni ile uzun süreli kortikostreroid tedavi siklıkla kullanılmaktadır. Bu hastalarda altta yatan 
hastalığın şiddeti, birlikte bulunduğu damar ve kanama anomalileri ve kardiyomiyopati kaydedilmelidir. Uzun süreli veya intermittant kortikostreroid alan çocuklara cerrahiden 24 saat önce "stres dozu" verilmelidir. Operasyondan bir gece önce oral $25-50 \mathrm{mg} / \mathrm{m} 2$ prednizon ve İV: yol açıldıktan sonra da 25-50 $\mathrm{mg} / \mathrm{m} 2$ hidrokortizon stres dozu olarak verilmelidir.

Aşılar Çocuğun aşıları da sorgulanmalıdır. Anestezi ve cerrahi stres immün sistemi baskıladıkları için elektif cerrahiler bu süreçte ertelenmelidir [25].

Laboratuvar incelemeler Laboratuvar uygulamaları için standartlar konulmaya çalışılmışsa da preoperatif değerlendirmede üzerinde fikir birliğine ulaşılmıș laboratuvar inceleme standard 1 yoktur. Preoperatif rutin laboratuvar testlerine yeterince anlamlı olmadiğı, zaman, maliyet kaybı açısından karşı çıkanlar vardır. Laboratuvar incelemeler hastanın preoperatif değerlendirilmesindeki verileri ve operasyonun özellikleri göz önüne alınarak şekillendirilmesinin daha doğru olacağı yönündedir. Sağlıklı çocukta laboratuvar tetkiki olarak genelde hemoglobin ve hematokrit yeterli olurken, hikayesinde anomali olan çocuklarda diğer tetkikler istenebilir [26, 27]. Rutin preoperatif akciğer grafisi de çocukların radyasyon maruziyetlerini azaltmak amaciyla hastalardan istenmemelidir [28].

Psikolojik değerlendirme ve hazırlık Preoperatif dönemde çocuk ve ailesinde değişik nedenlerden kaynaklanan anksiyete vardır. Altı aylıktan küçük bebeklerde kısa süreli hospitalizasyon sorun olușturmazken sürenin uzaması bebek anne ilișkisini olumsuz etkilemektedir. Anksiyete, olumsuz etkilenme 1-3 yaş arasında maksimumdur.
$\mathrm{Bu}$ yaş grubunda çocuk olanları farkeder ama kavrayamaz, psikolojik hazırliktan yeterince yararlanamaz. Aileye ulaşabilmek daha kolaydır ve ailenin anksiyetesi azaltılınca bu çocuğa yansiyacaktır.

Premedikasyon Premedikasyon istenmeyen otonomik refleksleri bloke eder, bulant1, ögürme, kusma, kardiyak aritmiler, solunum bozuklukları, laringeal ve bronşial spazm, tükürük ve üst solunum yolu sekresyonlarının artmas1 gibi refleks aktivitenin azaltılmasında fayda sağlar. Ayrıca çocuklarda cerrahi korku ve aileden ayrilma korkusunu azaltmada faydalı olabilir. Yine indüksiyon esnasında ailenin çocuğun yanında bulunması da faydalı olabilir [29].

Açlık süreleri Hastaların preoperatif hazırlıkta aç bırakılmalarının amacı özellikle indüksiyon esnasında mide içeriğinin aspirasyonunu önlemektir. $\mathrm{Bu}$ süre berrak sıvılar için 2 saat, 6 aydan küçük infantlarda anne sütü ve mama için 4 saat, 6 aydan büyük infantlar ve çocuklar için 6 saattir [30, 31]. Berrak sıvıların aspirasyon pnömonisi riski daha düşüktür. ayrıca çocukların açlığı tolere etmesine yardımcı olurlar ve perioperatif hipoglisemiden korurlar [32, 33].

\section{Sonuç}

Preoperatif değerlendirme anestezi veya sedasyon uygulanacak hastalarda zorunludur. Hastalardan istenecek testler, elde edilen muayene bulgularına göre daha seçici ve az olmalıdır. Çocuk hastaların anatomik ve fizyolojik farklılıklarının olduğu ve erişkin hastalardan farklı yaklaşılması gerektiği hiçbir zaman unutulmamalıdır. 


\section{KAYNAKLAR}

1. Ferrari, L.R. (2004). Preoperative evaluation of pediatric surgical patients with multisystem considerations. Anesth Analg, 99(4):1058-69.

2. Committee on, S. et al., (2012). Practice advisory for preanesthesia evaluation: an updated report by the American Society of Anesthesiologists Task Force on Preanesthesia Evaluation. Anesthesiology, 116(3):522-38.

3. Von Ungern-Sternberg, B.S. and W. Habre, (2007). Pediatric anesthesia-potential risks and their assessment: part II. Paediatr Anaesth, . 17(4):31120.

4. Mamie, C., et al., (2004). Incidence and risk factors of perioperative respiratory adverse events in children undergoing elective surgery. Paediatr Anaesth.

14(3): 218-24.

5. Cohen, M.M. Cameron, C.B. and Duncan, P.G. (1990). Pediatric anesthesia morbidity and mortality in the perioperative period. Anesth Analg. 70(2): 160-7.

6. Bancalari, E. and Clausen, J. (1998). Pathophysiology of changes in absolute lung volumes. Eur Respir J. 12(1): 248-58.

7. Olsson, G.L. and Hallen, B. (1984). Laryngospasm during anaesthesia. A computer-aided incidence study in 136,929 patients. Acta Anaesthesiol Scand. 28(5):567-75.

8. Olsson, G.L.(1987). Bronchospasm during anaesthesia. A computer-aided incidence study of 136,929 patients. Acta Anaesthesiol Scand. 31(3):24452.

9. Holzman, R.S. (1994). Morbidity and mortality in pediatric anesthesia. Pediatr Clin North Am. 41(1):239-56.

10. Stocks, J. (1999). Respiratory physiology during early life. Monaldi Arch Chest Dis. 54(4):358-64.
11. Nishino, T. Tagaito, Y. and Isono, S. (1996). Cough and other reflexes on irritation of airway mucosa in man. Pulm Pharmacol. 9(5-6):285-92.

12. Rabbette, P.S. Costeloe, K.L. and Stocks, J. (1991). Persistence of the Hering-Breuer reflex beyond the neonatal period. $J$ Appl Physiol (1985). 71(2):474-80.

13. Tait, A.R., et al., (2001). Risk factors for perioperative adverse respiratory events in children with upper respiratory tract infections. Anesthesiology. 95(2):299-306.

14. Skolnick, E.T. et al., (1998). Exposure to environmental tobacco smoke and the risk of adverse respiratory events in children receiving general anesthesia.Anesthesiology.88(5):114453.

15. Tait, A.R. and Malviya, S.(2005). Anesthesia for the child with an upper respiratory tract infection: still a dilemma? Anesth Analg.100(1): 59-65.

16. Aquilina, A.T., et al., (1980). Airway reactivity in subjects with viral upper respiratory tract infections: the effects of exercise and cold air. Am Rev Respir Dis. 122(1):3-10.

17. Collier, A.M., et al.(1978).Spirometric changes in normal children with upper respiratory infections. Am Rev Respir Dis. 117(1):47-53.

18. Rolf, N. and Cote, C.J. (1992). Frequency and severity of desaturation events during general anesthesia in children with and without upper respiratory infections. J Clin Anesth. 4(3):200-3.

19. Maxwell, L.G. (2004). Age-associated issues in preoperative evaluation, testing, and planning: pediatrics. Anesthesiol Clin North America. 22(1):27-43.

20. Farbod, F. Kanaan, H. and Farbod, J. (2009). Infective endocarditis and antibiotic prophylaxis prior to dental/oral procedures: latest revision 
to the guidelines by the American Heart Association published April 2007. Int J Oral Maxillofac Surg. 38(6): 626-31.

21. Chadwick, V. and Wilkinson, K.A. (2004). Diabetes mellitus and the pediatric anesthetist. Paediatr Anaesth. 14(9):716-23.

22. Smith, H.L. Meldrum, D.J. and Brennan, L.J. (2002). Childhood obesity: a challenge for the anaesthetist? Paediatr Anaesth. 12(9):750-61.

23. Lazarus, R. et al., (1997). Effects of body fat on ventilatory function in children and adolescents: crosssectional findings from a random population sample of school children. Pediatr Pulmonol. 24(3):187-94.

24. Pinhas-Hamiel, O. et al., (1996). Increased incidence of non-insulindependent diabetes mellitus among $\begin{array}{llll}\text { adolescents. } J & \text { Pediatr. } & 128\end{array}$ (5 Pt 1):608-15.

25. Salo, M. (1992). Effects of anaesthesia and surgery on the immune response. Acta Anaesthesiol Scand. 36(3):201-20.

26. Macpherson, D.S. (1993). Preoperative laboratory testing: should any tests be "routine" before surgery? Med Clin North Am. 77(2):289-308.

27. Meneghini, L. et al., (1998). The usefulness of routine preoperative laboratory tests for one-day surgery in healthy children. Paediatr Anaesth. $8(1): 11-5$.

28. Preoperative chest radiographs. (1983). Pediatrics. 71(5):858.

29. Von Ungern-Sternberg, B.S. and Habre, W. (2007). Pediatric anesthesia - potential risks and their assessment: part I. Paediatr Anaesth.17(3):206-15.

30. Splinter, W.M. and Schreiner, M.S. (1999). Preoperative fasting in children. Anesth Analg. 89(1):80-9.

31. Litman, R.S. Wu C.L. and Quinlivan, J.K. (1994). Gastric volume and $\mathrm{pH}$ in infants fed clear liquids and breast milk prior to surgery. Anesth Analg. 79(3): 482-5.

32. Splinter, W.M. Stewart, J.A. and Muir, J.G. (1989). The effect of preoperative apple juice on gastric contents, thirst, and hunger in children. Can J Anaesth. 36(1):55-8.

33. Splinter, W.M. Stewart, J.A. and Muir, J.G. (1990). Large volumes of apple juice preoperatively do not affect gastric $\mathrm{pH}$ and volume in children. Can J Anaesth, 37(1):36-9. 